\title{
Implementation of the methods of problematic education in classes of physics
}

\author{
S.J.Bazarova ${ }^{1}$, F.Kh.Baychayev ${ }^{2}$, \\ ${ }^{1}$ Doctor of Science in Pedagogue, prof. Head of the Department of quality control of education of Navoi State \\ Mining Institute \\ ${ }^{2}$ Assistant of the Department" General Physics", Navoi State Mining Institute
}

\begin{abstract}
The work discusses problematic education in the classes of physics increases the level of training of specialists and play important role in forming basic training and creating scientific outlook of future specialist.
\end{abstract}

Keywords: education, problem—developing training, personnel training, production, competence.

\section{INTRODUCTION}

Modern science and technology is developing at an unusually fast pace. Production methods and technologies, equipment used are regularly improved and updated, and what is especially important, the requirements for engineering and technical specialties are qualitatively changed.

All this could not but lead to a sharp increase in the requirements that are imposed on the modern course of physics. These requirements are expressed in increasing the scientific and theoretical level of the course. This time has significantly changed the position of the physics course in the system of training a modern specialist. If earlier the physics course was mainly the Foundation on which engineering training buildings were built, now the physics course, while fully retaining this value, has become at the same time an integral part of training a specialist for a specific field.

Physics begins where the student begins to consider physical phenomena quantitatively, using sign models: quantities, formulas, graphs. In physics, a sign or symbol becomes a student's main tool for constructing mental images of real objects and processes. In the course of this activity, the student reveals the conditions of the origin of the acquired concepts, reproduces the process of their birth and development, and masters the General methods of actions for their construction. This process of mastering knowledge develops the student's theoretical thinking, imagination and, most importantly, creative qualities.

The ways of development of the mining and metallurgical industry of modern production are very closely intertwined with physics, so miners or metallurgists should be able to master physics to such an extent that they are able to actively and knowledgeably apply the achievements of scientific and technological progress in their production activities, because on the basis of the achievements of physical science, fundamentally new and more advanced production methods, devices and installations are developed.

The teacher must link the development of science with the production needs of the era. One of the ways to improve physics classes is the widespread introduction of problem-based learning methods.

For problem-based learning it is necessary to select topics from physics, depth and strength of learning which the most professionally significant i.e. based on the study of teacher qualifications in the field.

With problem-based learning, the teacher, using special methodological techniques, includes students in active intellectual activity from the very beginning of classes, i.e. knowledge is not given in a ready-made form, but is acquired by them in the process of a cognitive situation. This knowledge in solving a problem situation is constantly deepened, consolidated, creating a new, higher level of creative activity of the student, forming their ability to research.

The structure of the problem lesson includes: updating knowledge; creating a problem situation and setting the problem; making suggestions and justifying the hypothesis, proving the hypothesis; checking the correctness of solutions to the problem.

Problem-based learning is the sum of different methods used. The teacher's choice of a particular method or combination of methods in a particular lesson depends on the content of the educational material, the level of training of the student, and the teacher's methodological skills.

This method is used when the teacher seeks to teach students individual elements of solving a problem, to organize a partial search for new knowledge and methods of action. For Example, when studying the topic of acceleration of free fall, it is necessary... it is problematic to raise the question: is it possible to determine the location of minerals by measuring $\mathrm{g}$ ?

Further, the following are determined with the students 'forces::

There are several methods for more accurate determination of $\mathrm{g}$ - acceleration of gravity. For this purpose, we can use a simple mathematical pendulum - the system consists of a small weight suspended on a thin but inextensible thread. The period of the pendulum's oscillation is inversely proportional to the square root of the acceleration of gravity $\mathrm{g}$. This circumstance allowed us to accurately determine $\mathrm{g} T=2 \pi \sqrt{\ell / g}$ by measuring the 
period of the pendulum's oscillation

The value of the acceleration of gravity on the earth's surface has two regular measurements:

a) at the same height above sea level, $g$ is greatest at the poles, where $g$ is $9.83 \mathrm{~m} / \mathrm{s}^{2}$ at the equator, $g$ is least $9.78 \mathrm{~m} / \mathrm{s}^{2}$. It follows that the weight of any body is greatest at the pole because the body will be closer to the center of the Earth and smallest at the equator, weakening the centrifugal force.

b) $g$ changes with height according to the formula $\left.g=j(M / R+h)^{2}\right)$ that is, at the same latitude, the acceleration of gravity should take the same value.

As you know, the weight of the body: in different places on the Earth's surface is different due to the fact that the value of $\mathrm{g}$ in different places is different. This means that both the force of gravity and the direction of this force change. Gravity acts in the direction of the Earth - this direction is called vertical. In this case, this vertical deviates from the norm, which can be checked by special maps of geologists, on which the ideal shape of the Earth is built based on data on values. Gravity anomalies are obtained by measuring these quantities. To do this, we can consider the earth as a sphere of radius $\mathrm{R}$, consisting of homogeneous density of Arctic layers.

Let's denote the value of gravity at sea level by $\mathrm{g}_{0}$, and the value of gravity at height $\mathrm{H}$, by $\mathrm{g}_{\mathrm{H}}$, then

$$
\begin{aligned}
& \mathrm{P}=\mathrm{mg}_{0} \quad F=G \frac{M m}{R^{2}} \\
& \text { Equalizing, } \mathrm{P}=\mathrm{F} \text { we get } \quad m g_{0}=G \frac{m M}{R^{2}} \\
& g_{0}=\frac{G M}{R^{2}} \quad \text { on this basis, } \quad g_{H}=\frac{G M}{(R+H)^{2}}
\end{aligned}
$$

The height correction is as follows:

$$
\Delta g=g_{0}-g_{H}=G M\left[\frac{1}{R^{2}}-\frac{1}{(R+H)^{2}}\right]=\frac{G M}{R^{2}}\left[1-\left(\frac{R}{R+H}\right)^{2}\right]=g_{0}\left[1-\frac{1}{\left(1+\frac{H}{R}\right)^{2}}\right]
$$

\section{Given the Newton binomial formula one can write}

$$
\frac{1}{\left(1+\frac{H}{R}\right)^{2}}=\left(1+\frac{H}{R}\right)^{-2}=1-\frac{2 H}{R}+3\left(\frac{H}{R}\right)^{2} \ldots
$$

In this decomposition, we can restrict ourselves to the first two terms, then we get $\Delta g=\frac{2 g_{0} H}{R}$;

This means that we must take into account the force of gravity, that is, the inhomogeneities of the mass distribution near the measurement site. For example, on The surface of the earth above the anticlinar fold, the core, which is composed of dense limestones and is covered by a thickness of less dense sand and clay rocks, will have an anomaly of gravity, i.e. the gravity will be maximum. The magnitude of the anomaly depends on the elevation amplitude and the difference in rock density.

Let's assume that the area under study has a salt dome, the core of which is co - ordinated with rock salt- a relatively low density rock. In this case, there will be a negative gravity anomaly or a minimum of gravity above the dome. Above ore deposits, there may be gravitational anomalies mostly positive (maximum gravity), since the density of ores is usually greater than the density of the host rocks.

For prospecting and exploration of oil deposits measurement of the force of gravity is usually used in combination with seismic.

An oil field confined to layers of sand and clay rocks (reservoirs) that form a rise above the vault or in the side part of the dome. The density of rock salt is constant, which is due to its fluidity (under pressure, salt flows, and does not condense). In most cases, the density of rocks located on the side of the dome is higher than the density of salt, for example, for sandy-clay salt, a pronounced minimum of gravity appears in the dome. Theoretically, at the same latitude, the acceleration of gravity should take the same values. But when determining gravity, the inhomogeneity of the mass distribution in the vicinity of the measurement site is taken into account.

Based on these considerations, we can say that if there are heavy masses near the measurement, then $g$ will be the largest, otherwise it will be the smallest.

Thus, the use of these results makes it possible to increase the role of professionally-oriented training in higher technical universities:

With regular improvement and updating of production technologies, equipment used and, most importantly, qualitative changes in the requirements for engineering and technical specialists, it becomes quite obvious that only Volume 3, Issue X, October $2020 \mid 280$ 
those graduates who have received a sufficiently broad and deep training in the course of training can quickly navigate and successfully work in production. Thus, problem - developing training increases the level of training and plays an important role in the formation of fundamental training and development of the scientific Outlook of the future specialist.

Based on the results of scientific research:

pedagogical bases for improving the competence of future specialists in the mining and metallurgical industry with the help of problem-developing training and professionally oriented tasks have been Developed;

the high efficiency of practical training conducted on the basis of professionally-oriented training technologies is proved;

innovative approaches to practical training are considered, taking into account their specific features, and requirements for professionally-oriented tasks for higher technical educational institutions are developed.

\section{REFERENCES:}

1. Bazarova S. J. Technologies of professionally-oriented training in higher education. Monograph. - Tashkent: publishing house "Science and technology", 2006. - P. 114

2. Bazarova S. J., Khaletskaya O. Unity of theory and practice: connection of education with production. // "Mountain Bulletin of Uzbekistan". - Navoi, 2003. No. 3. -Pp. 75-78

3. Bazarova S. J. Design of professionally-oriented training technology. // "Science and education of southern Kazakhstan". - Kazakhstan, 2007. - No. 3. -Pp. 26-28

4. Bazarova S. J., Khaletskaya O. Integration of science and production. // Materials of the International remote conference "Mining, oil and geoecological education in the 21st century". - Moscow, Russian Federation. 2004. -Pp. 147-151.

5. Bazarova S. J. Agzamov Sh. K. Improvement of personnel training in continuous education // Collection of materials of the II-all-Russian scientific and practical conference Continuing education: regional aspect, interaction with employers.-Yekaterinburg, 2006. Pp. 9-11. 